\title{
Factors related to suboptimal recovery of renal function after living donor nephrectomy: a retrospective study
}

Sho Nishida ${ }^{1}{ }^{2}$, Yuji Hidaka ${ }^{1}$, Mariko Toyoda ${ }^{3}$, Kohei Kinoshita ${ }^{1}$, Kosuke Tanaka ${ }^{1}$, Chiaki Kawabata ${ }^{3}$, Satoshi Hamanoue ${ }^{3}$, Akito Inadome², Hiroshi Yokomizo', Asami Takeda ${ }^{4}$, Soichi Uekihara ${ }^{3}$ and Shigeyoshi Yamanaga ${ }^{*^{*}}$ (D)

\begin{abstract}
Background: The renal function of the remaining kidney in living donors recovers up to 60 70\% of pre-donation estimated-glomerular filtration rate (eGFR) by compensatory hypertrophy. However, the degree of this hypertrophy varies from donor to donor and the factors related to it are scarcely known.

Methods: We analyzed 103 living renal transplantations in our institution and divided them into two groups: compensatory hypertrophy group [optimal group, 1 -year eGFR $\geq 60 \%$ of pre-donation, $n=63$ ] and suboptimal compensatory hypertrophy group (suboptimal group, 1-year eGFR $<60 \%$ of pre-donation, $n=40$ ). We retrospectively analyzed the factors related to suboptimal compensatory hypertrophy.
\end{abstract}

Results: Baseline eGFRs were the same in the two groups (optimal versus suboptimal: $82.0 \pm 13.1 \mathrm{ml} / \mathrm{min} / 1.73 \mathrm{~m}^{2}$ versus $83.5 \pm 14.8 \mathrm{ml} / \mathrm{min} / 1.73 \mathrm{~m}^{2}, p=0.588$ ). Donor age (optimal versus suboptimal: $56.0 \pm 10.4$ years old versus $60.7 \pm 8.7$ years old, $p=0.018$ ) and uric acid (optimal versus suboptimal: $4.8 \pm 1.2 \mathrm{mg} / \mathrm{dl}$ versus $5.5 \pm 1.3 \mathrm{mg} / \mathrm{dl}, p=$ 0.007 ) were significantly higher in the suboptimal group. The rate of pathological chronicity finding on 1-h biopsy (ah $\geqq 1 \cap \mathrm{ct}+\mathrm{ci} \geqq 1$ ) was much higher in the suboptimal group (optimal versus suboptimal: $6.4 \%$ versus $25.0 \%, p=$ 0.007). After the multivariate analysis, the pathological chronicity finding [odds ratio (OR): $4.8,95 \%$ confidence interval (Cl): 1.3-17.8, $p=0.021$ ] and uric acid (per $1.0 \mathrm{mg} / \mathrm{dl}, \mathrm{OR}: 1.5,95 \% \mathrm{Cl}: 1.1-2.2, p=0.022$ ) were found to be independent risk factors for suboptimal compensatory hypertrophy.

Conclusion: Chronicity findings on baseline biopsy and higher uric acid were associated with insufficient recovery of the post-donated renal function.

Keywords: Renal function, Living donor, Kidney transplant

\section{Background}

End-stage renal disease (ESRD) substantially increases the risk of death and cardiovascular disease [1-4]. Renal transplantation is the best treatment option for ESRD [5]. In Japan, due to the shortage of deceased donors, $89.2 \%$ of renal transplants are from living donors [6]. To minimize the risk of ESRD after donation, the selection of living donors requires great care [7].

\footnotetext{
* Correspondence: yamanaga@kumamoto-med.jrc.or.jp

1 Department of General Surgery, Japanese Red Cross Kumamoto Hospital,

2-1-1 Nagamine-minami, Higashi-ku, Kumamoto 861-8520, Japan

Full list of author information is available at the end of the article
}

The renal function of the remaining kidney in living donors usually recovers up to $60 \sim 70 \%$ of baseline function through a compensatory hypertrophy mechanism $[8,9]$. However, the degree of this compensatory hypertrophy varies from donor-to-donor. The reason for this between-donor difference is unclear; however, considering the wide range of the health status among living donors, the presence of subtle metabolic syndromes or preclinical renal diseases prior to transplantation are possible, [5] which could affect functional renal recovery after the donation.

Despite meticulous efforts to avoid adverse events for living donors, the 15-year risk of ESRD in donors is 3.5

(c) The Author(s). 2019 Open Access This article is distributed under the terms of the Creative Commons Attribution 4.0 International License (http://creativecommons.org/licenses/by/4.0/), which permits unrestricted use, distribution, and 
to 5.3 times higher than that of a matched population $[10,11]$. Therefore, accurate estimation of the residual glomerular filtration rate (eGFR) is crucial in order to maintain a donor's life-long renal function and to prevent cardiovascular events.

We hypothesized that donors' baseline characteristics and findings on baseline renal biopsy would predict the extent of compensatory hypertrophy after renal donation $[5,10]$. Therefore, our aim in this study was to identify the factors related to a suboptimal recovery of renal function in living donors after donation.

\section{Methods}

\section{Study population}

We conducted a retrospective analysis of consecutive 111 cases of living renal transplantations performed at our institution from 2011 to 2016. The donor's split renal function was calculated by using MAG3 scintigraphy to determine the side of the kidney graft. Living donor nephrectomy was performed using a pure retroperitoneoscopic approach. Of these 111 cases, 8 cases were excluded due to unavailability of baseline biopsies $(n=3)$ and loss to follow-up $(n=5)$. The remaining 103 cases were divided into two groups: the compensatory hypertrophy group [optimal group, with a 1-year eGFR $\geq 60 \%$ of the pre-donation eGFR, $n=63$ ] and suboptimal compensatory hypertrophy group (suboptimal group, with a 1 -year eGFR $<60 \%$ of pre-donation eGFR, $n=$ 40). The cut-off eGFR of $60 \%$ for classification of suboptimal compensatory hypertrophy was based on a previous study that reported a typical range of postdonation eGFR of $62.5 \sim 67 \%$ from baseline renal function [8]. We evaluated between-group differences in baseline characteristics and findings through the baseline biopsy obtained during kidney transplantation.

\section{Definition of the measurements}

EGFR was calculated using the following formula for the modified IDMS-MDRD Study equation for Japanese individuals: eGFR $(\mathrm{ml} / \mathrm{min} / 1.73 \mathrm{~m} 2)=194 \times($ Serum creatinine $)^{-1.094} \times(\text { Age })^{-0.287} \times 0.739$ (if female) [12]. EGFRs were assessed at the initial visit and the annual visit at one year after the donation. Japan Diabetes Society (JDS) HbA1c values were converted into National Glycohemoglobin Standardization Program (NGSP) HbA1c values using the following formula, as recommended by the JDS: NGSP value $(\%)=1.02 \times$ JDS value $(\%)+0.25 \%$. We diagnosed hypertension as follows using the criteria defined by the Japanese Society of Hypertension (JSH): systolic blood pressure $\geq 140 \mathrm{mmHg}$ or diastolic blood pressure $\geq 90 \mathrm{mmHg}$ [13]. Hyperlipidemia was defined as follows using the criteria recommended by the Japan Atherosclerosis Society; low-density lipoprotein cholesterol (LDL-C) $\geq 140 \mathrm{mg} / \mathrm{dl}$, high-density lipoprotein cholesterol (HDL-C) $\leq 40 \mathrm{mg} / \mathrm{dl}$, or triglycerides (TG) $\geq 150 \mathrm{mg} / \mathrm{dl}$ [14]. Salt consumption per day and estimated fractional excretion of sodium in urine were calculated using the formula recommended by the Japanese Society of Hypertension [13]. Hyperuricemia was defined as serum uric acid level $\geq 7.0 \mathrm{mg} / \mathrm{dl}$ in men and $\geq 6.0 \mathrm{mg} /$ $\mathrm{dl}$ in women [15]. In our study, 14 patients were diagnosed with hyperuricemia before donation, and none of them underwent uric acid treatment.

\section{Pathological diagnosis}

Baseline kidney biopsy was defined as biopsy performed at $1 \mathrm{~h}$ after re-perfusion during kidney transplant operation. No other biopsies with different timings or causes (e.g. 1-year protocol biopsy or episode biopsy) were included in this study. Pathological findings were evaluated using the current Banff score [16] of the chronic renal changes (at $1 \mathrm{~h}$ ) identified in the baseline biopsy specimen, namely: interstitial fibrosis (ci), tubular atrophy (ct), arteriolar hyalinosis (ah), and glomerular atrophy. Based on the percentage of the renal cortical area visible, the ci was classified as minimal ( $\leqq 5 \%)$, mild (6-25\%), moderate $(26-50 \%)$, or severe $(\geqq 50 \%)$, which corresponded to Banff scores of ci of ci-0, ci-1, ci-2, and ci-3, respectively. $\mathrm{Ct}$ was similarly categorized according to Banff scores of ct- 0 , ct- 1 , ct- 2 , and ct- 3 . Ah was classified as none, mild-to-moderate, moderate-to-severe, or severe, corresponding to a Banff score of ah 0 , ah 1 , ah 2 , and ah 3, respectively. Glomerular atrophy was evaluated as the proportion of atrophic glomeruli to the total number of glomeruli in the specimen. Baseline biopsy data were collected retrospectively from the pathology reports.

\section{Statistical analysis}

Between-group differences were evaluated using Student's t-test for continuous data, and the chi-squared $\left(x^{2}\right)$ test for categorical data. We performed a logistic regression analysis, using a forward selection method for sex, body surface area (BSA), and the characteristics with significant between-group differences. All analyses were performed using SPSS (version 20, IBM, Chicago, Illinois, USA). Two-tailed $p$-values $\leq 0.05$ were considered statistically significant. Values are expressed as mean \pm standard deviation, unless otherwise specified.

\section{Results}

\section{Baseline characteristics}

The baseline characteristics are shown in Table 1, with the following variables having a higher value in the suboptimal than optimal group: age (optimal versus suboptimal, $56.0 \pm 10.4$ years old versus $60.7 \pm 8.7$ years, $p=$ $0.018)$; HbA1c ( $5.6 \pm 0.3 \%$ versus $5.8 \pm 0.3 \%$, respectively, $p=0.016)$ and uric acid $(4.8 \pm 1.2 \mathrm{mg} / \mathrm{dl}$ versus $5.5 \pm 1.3$ 
Table 1 Baseline characteristics of living donors

\begin{tabular}{|c|c|c|c|}
\hline & Optimal group & Suboptimal group & p-value \\
\hline & $n=63$ & $n=40$ & \\
\hline Age (years) & $56.0 \pm 10.4$ & $60.7 \pm 8.7$ & 0.018 \\
\hline Male, n (\%) & $19(30.2)$ & $18(45.0)$ & 0.126 \\
\hline Height (cm) & $159.8 \pm 8.3$ & $160.3 \pm 8.7$ & 0.769 \\
\hline Weight (kg) & $59.3 \pm 10.9$ & $61.5 \pm 10.7$ & 0.325 \\
\hline Body mass index $\left(\mathrm{kg} / \mathrm{m}^{2}\right)$ & $23.2 \pm 3.4$ & $23.9 \pm 3.3$ & 0.290 \\
\hline Body surface area $\left(\mathrm{m}^{2}\right)$ & $1.6 \pm 0.2$ & $1.6 \pm 0.2$ & 0.399 \\
\hline HbA1c (\%) & $5.6 \pm 0.3$ & $5.8 \pm 0.3$ & 0.016 \\
\hline Hypertension, n (\%) & $10(15.9)$ & $7(17.5)$ & 0.828 \\
\hline Hyperlipidemia, $n$ (\%) & $10(15.9)$ & $7(17.5)$ & 0.828 \\
\hline History of smoking, $n(\%),(n=73)$ & $12(28.0)$ & $6(20.0)$ & 0.441 \\
\hline eGFR (mL/min/1.73 m²) & $82.0 \pm 13.1$ & $83.5 \pm 14.8$ & 0.588 \\
\hline Uric acid (mg/dl) & $4.8 \pm 1.2$ & $5.5 \pm 1.3$ & 0.007 \\
\hline Blood nitrogen urea (mg/dl) & $13.5 \pm 4.7$ & $14.0 \pm 3.4$ & 0.582 \\
\hline Side of kidney (right), $n$ (\%) & $5(8.3)$ & $3(7.5)$ & 1.0 \\
\hline Urine protein (mg/day), $(n=74)$ & $74.1 \pm 47.5$ & $78.1 \pm 56.9$ & 0.746 \\
\hline 24-h creatinine clearance (mg/dl) & $113.6 \pm 35.2$ & $103.5 \pm 23.8$ & 0.089 \\
\hline mGFR via MAG3 scintigraphy $\left(\mathrm{ml} / \mathrm{min} / 1.73 \mathrm{~m}^{2}\right)$ & $114.2 \pm 21.9$ & $111.6 \pm 20.0$ & 0.554 \\
\hline
\end{tabular}

eGFR estimated glomerular filtration rate: $194 \times$ (serum creatinine) $-1.094 \times$ (age) $-0.287 \times 0.739$ (if female)

Table 2 Chronic histological changes

\begin{tabular}{|c|c|c|c|}
\hline & Optimal group & Suboptimal group & \multirow{2}{*}{$\begin{array}{l}\mathrm{p}- \\
\text { value }\end{array}$} \\
\hline & $n=63$ & $n=40$ & \\
\hline ct0, n (\%) & $48(76.2)$ & $23(57.5)$ & \multirow[t]{3}{*}{0.084} \\
\hline 1, n (\%) & $15(23.8)$ & $16(40.0)$ & \\
\hline $2, \mathrm{n}(\%)$ & $0(0.0)$ & $1(2.5)$ & \\
\hline ci0, n (\%) & $56(88.9)$ & $32(80.0)$ & \multirow[t]{3}{*}{0.281} \\
\hline $1, \mathrm{n}(\%)$ & $7(11.1)$ & $7(17.5)$ & \\
\hline $2, \mathrm{n}(\%)$ & $0(0.0)$ & $1(2.5)$ & \\
\hline aho, n (\%) & $39(61.9)$ & $23(57.5)$ & \multirow[t]{4}{*}{0.466} \\
\hline $1, \mathrm{n}(\%)$ & $9(14.3)$ & $7(17.5)$ & \\
\hline $2, \mathrm{n}(\%)$ & $12(19.0)$ & $10(25.0)$ & \\
\hline $3, \mathrm{n}(\%)$ & $3(4.8)$ & $0(0.0)$ & \\
\hline $\mathrm{ct}+\mathrm{ci} 0, \mathrm{n}(\%)$ & $47(74.6)$ & $22(55.0)$ & \multirow[t]{5}{*}{0.156} \\
\hline 1, n (\%) & $10(15.9)$ & $11(27.5)$ & \\
\hline $2, \mathrm{n}(\%)$ & $6(9.5)$ & $6(15.0)$ & \\
\hline $3, \mathrm{n}(\%)$ & $0(0.0)$ & $0(0.0)$ & \\
\hline 4, n (\%) & $0(0.0)$ & $1(2.5)$ & \\
\hline Glomerular atrophy rate, \% & $9.1 \pm 10.1$ & $11.4 \pm 10.5$ & 0.280 \\
\hline Number of glomeruli per biopsy & $20.7 \pm 9.4$ & $18.1 \pm 7.5$ & 0.123 \\
\hline $\mathrm{ct}+\mathrm{ci} \geqq 1 \cup$ ah $\geqq 1, \mathrm{n}(\%)$ & $36(57.1)$ & $25(62.5)$ & 0.590 \\
\hline $\mathrm{ct}+\mathrm{ci} \geqq 1 \cap \mathrm{ah} \geqq 1, \mathrm{n}(\%)$ & $4(6.4)$ & $10(25.0)$ & 0.007 \\
\hline
\end{tabular}


$\mathrm{mg} / \mathrm{dl}$, respectively, $p=0.007$ ). Other variables (hypertension, hyperlipidemia, body mass index, and BSA) were not different between the groups, including baseline eGFR (optimal versus suboptimal. $82.0 \pm 13.1 \mathrm{ml} /$ $\min / 1.73 \mathrm{~m}^{2}$ versus $83.5 \pm 14.8 \mathrm{ml} / \mathrm{min} / 1.73 \mathrm{~m}^{2}, \quad p=$ $0.588)$.

\section{Histological findings}

The chronic histological changes on baseline biopsy are shown in Table 2. In terms of ah, ci, and ct, there were no significant differences between the two groups. The combination of ct and ci score ( $\mathrm{ct}+\mathrm{ci} \geqq 1$ ) tended to be higher in the suboptimal group, but this between-group difference was not significant. However, the incidence of having both an ah score and ct + ci score $\geqq 1(\mathrm{ah} \geqq 1 \cap$ $c t+c i \geqq 1$ ) was significantly higher in the suboptimal than the optimal group (optimal versus suboptimal, $6.4 \%$ versus $25.0 \%, p=0.007)$. The rate of glomerular atrophy was not significantly different between the two groups (optimal versus suboptimal: $9.1 \%$ versus $11.4 \%, p=$ $0.280)$.

\section{Post-donation eGFR}

Changes in renal function at 1 year after donation are shown in Table 3. EGFR, HbA1c, blood urea nitrogen, and uric acid are significantly higher in the suboptimal group.

EGFR was about $10 \mathrm{ml} / \mathrm{min} / 1.73 \mathrm{~m}^{2}$ lower in the suboptimal than optimal group (optimal versus suboptimal, $55.6 \pm 9.4 \mathrm{ml} / \mathrm{min} / 1.73 \mathrm{~m}^{2}$ versus $46.0 \pm 8.3 \mathrm{ml} / \mathrm{min} /$ $\left.1.73 \mathrm{~m}^{2}, p<0.001\right)$. The following variables were worse (higher) in the suboptimal than optimal group: uric acid (optimal versus suboptimal, $5.9 \pm 1.6 \mathrm{mg} / \mathrm{dl}$ versus $6.9 \pm$ $2.0 \mathrm{mg} / \mathrm{dl}, p=0.005)$ and blood urea nitrogen $(15.6 \pm 3.6$ $\mathrm{mg} / \mathrm{dl}$ versus $18.1 \pm 3.7 \mathrm{mg} / \mathrm{dl}$, respectively, $p=0.001$ ). HbA1c was also higher in the suboptimal than optimal group (optimal versus suboptimal, $5.6 \pm 0.3 \%$ versus $5.8 \pm 0.3 \%, \mathrm{p}=0.005)$.
Changes in values from pre-donation to 1-year postdonation are shown in Fig. 1 (A: eGFR, B: HbAlc, C: BUN and D: uric acid). BUN and Uric acid significantly elevated from pre to post in both optimal and suboptimal groups, but not true for HbA1c.

\section{Multivariate analysis}

The logistic regression analyses of the factors related to suboptimal compensatory hypertrophy are shown in Table 4, with the following variables retained as independent predictors: pathological chronicity score $(\mathrm{ah} \geqq 1$ $\cap \mathrm{ct}+\mathrm{ci} \geqq 1$; odds ratio (OR), 4.8, 95\%; confidence interval (CI) $1.3-17.8, p=0.021$ ) and uric acid (per $1.0 \mathrm{mg} / \mathrm{dl}$, OR, 1.5 ; 95\% CI, 1.1-2.2, $p=0.022$ ).

\section{Discussion}

We identified that hyperuricemia and chronic pathological changes ( $1 \mathrm{~h}$ after biopsy) are independent risk factors for suboptimal compensatory hypertrophy. Although pre-donation eGFRs were not different between the optimal and suboptimal groups, post-donation eGFR was nearly $10 \mathrm{ml} / \mathrm{min} / 1.73 \mathrm{~m}^{2}$ lower in the suboptimal group in contrast to that in the optimal group.

We defined suboptimal compensatory hypertrophy at 1 -year post-donation by an eGFR $<60 \%$ from baseline, based on the findings of Colin et al. [8] who reported that renal function after donation recovered to about $62.5 \sim 67 \%$ of baseline values, which is consistent with the findings in other studies $[8,9,17,18]$. In addition, the rate of GFR decline was significantly higher in patients with a baseline GFR $<50 \mathrm{ml} / \mathrm{min} / 1.73 \mathrm{~m}^{2}[2,19,20]$. The risk of cardiovascular events and uremic symptoms significantly increased in patients with an eGFR $<45 \mathrm{ml} /$ $\mathrm{min} / 1.73 \mathrm{~m}^{2},[3,20]$ with this risk increasing from 13 to $51 \%$, for an eGFR range of 7.5 to $15 \mathrm{ml} / \mathrm{min} / \mathrm{m}$ at 1 year [21]. Thus, by setting the cut-off at $60 \%$, we were able to differentiate donors close to chronic kidney disease (CKD) stage IIIA $\left(45 \sim 59 \mathrm{ml} / \mathrm{min} / 1.73 \mathrm{~m}^{2}\right)$ from those with CKD stage IIIB $\left(30 \sim 44 \mathrm{ml} / \mathrm{min} / 1.73 \mathrm{~m}^{2}\right)$, which

Table 3 One-year post-donation results

\begin{tabular}{|c|c|c|c|}
\hline & Optimal group & Suboptimal group & p- \\
\hline & $n=63$ & $n=40$ & \\
\hline eGFR $\left(\mathrm{mL} / \mathrm{min} / 1.73 \mathrm{~m}^{2}\right)$ & $55.6 \pm 9.4$ & $46.0 \pm 8.3$ & $<0.001$ \\
\hline Urine protein (mg/day) & $90.5 \pm 92.0(n=62)$ & $94.9 \pm 69.2(n=37)$ & 0.799 \\
\hline Uric acid (mg/dl) & $5.9 \pm 1.6$ & $6.9 \pm 2.0$ & 0.005 \\
\hline Blood nitrogen urea $(\mathrm{mg} / \mathrm{dl})$ & $15.6 \pm 3.6$ & $18.1 \pm 3.7$ & 0.001 \\
\hline HbA1c (\%) & $5.6 \pm 0.3$ & $5.8 \pm 0.3$ & 0.005 \\
\hline Estimated urine sodium excretion (mg/day) & $160.7 \pm 26.7(n=62)$ & $157.0 \pm 20.7(n=37)$ & 0.449 \\
\hline Estimated urine creatinine excretion (mg/day) & $1135.8 \pm 281.0(n=62)$ & $1134.3 \pm 254.3(n=37)$ & 0.422 \\
\hline Salt consumption per day (g/day) & $9.5 \pm 1.6(n=62)$ & $9.2 \pm 1.2(n=37)$ & 0.449 \\
\hline
\end{tabular}

eGFR estimated glomerular filtration rate: $194 \times$ (serum creatinine) $-1.094 \times$ (age) $-0.287 \times 0.739$ (if female) 

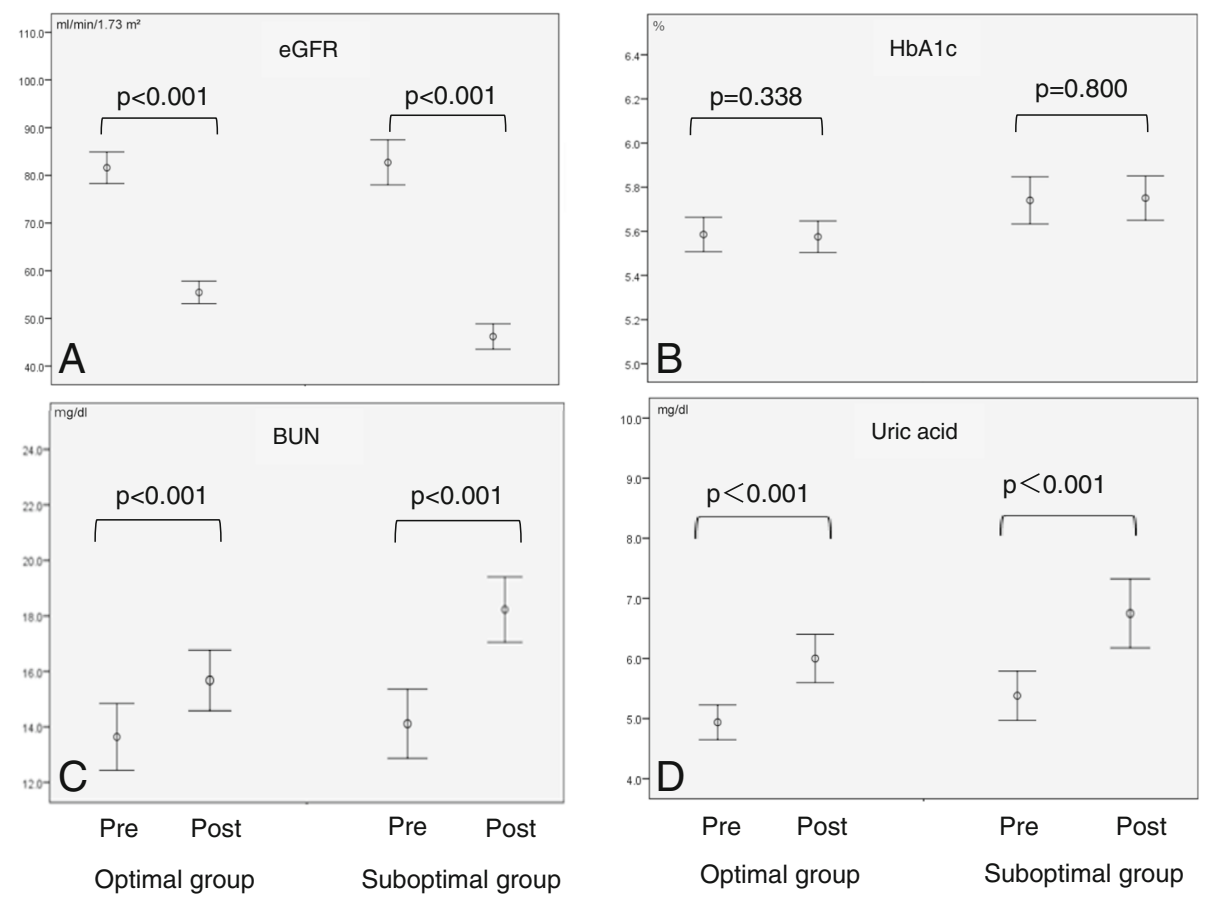

Fig. 1 Changes from pre-donation to post-donation of (a) eGFR (b) HbA1c (c) Blood Urea Nitrogen and (d) Uric acid

allowed us to identify the clinically relevant risk factors for suboptimal compensatory hypertrophy.

Interstitial fibrosis and tubular atrophy (IFTA) on baseline biopsy are more closely associated with lower long-term renal function in living donors than other abnormalities, including glomerulosclerosis and arteriolar hyalinosis [10]. However, IFTA is a pattern of injury that has many underlying causes, [22] which is why, in our study, we strived to specify the cause of IFTA by combining ct/ci and ah scores, which identified chronic ischemia induced by arteriosclerosis as the main cause of IFTA. Interestingly, the impact of this combination was independent of age, which is suggestive of a discrepancy between actual and biological age. Moreover, there was no correlation between chronicity score $(\mathrm{ah} \geqq 1 \cap \mathrm{ct}+$ $\mathrm{ci} \geqq 1)$ and glomerular atrophy. This result was consistent with the well-known fact that tubular atrophy is superior to glomerular pathology as a predictor of declining renal function [23].

It is impractical to obtain a baseline renal biopsy specimen as a component of the primary donor selection process. Instead, Ohashi et al. [5] showed that metabolic syndrome in donors is associated with chronic histological changes in the kidney and subsequent protracted recovery of kidney function after donation. In our study, hypertension, hyperlipidemia, and BMI were not significantly different between the two groups. Furthermore, HbA1c tended to be higher in the suboptimal group, but was not retained as an independent predictor on multivariate analysis. This may be due to the small number of donors. However, uric acid was an independent risk factor for suboptimal recovery of donor renal function. Although the uric acid levels of both groups were in the normal range in our study, this result suggests that

Table 4 Independent risk factors associated with suboptimal compensatory hypertrophy

\begin{tabular}{|c|c|c|c|c|}
\hline & \multicolumn{2}{|c|}{ Univariate analysis } & \multicolumn{2}{|c|}{ Multivariate analysis } \\
\hline & OR $(95 \% \mathrm{Cl})$ & $p$-value & OR $(95 \% \mathrm{Cl})$ & $p$-value \\
\hline$c t+c i>1 \cap a h \geqq 1$ & $4.9(1.4-17.0)$ & 0.012 & $4.8(1.3-17.8)$ & 0.021 \\
\hline Age (years, per 10) & $1.7(1.1-2.6)$ & 0.022 & & \\
\hline Sex (ref. female) & $1.9(0.8-4.3)$ & 0.128 & & \\
\hline Body surface area $\left(\mathrm{m}^{2}\right.$, per 0.1$)$ & $2.8(0.3-3.0)$ & 0.396 & & \\
\hline Uric acid (mg/dl, per 1.0) & $1.6(1.1-2.3)$ & 0.010 & $1.5(1.1-2.2)$ & 0.022 \\
\hline $\mathrm{HbA} 1 \mathrm{c}(\%$, per 0.1$)$ & $1.2(1.0-1.3)$ & 0.019 & & \\
\hline
\end{tabular}


higher uric acid levels may be related to the suboptimal recovery of renal function after nephrectomy. Iseki et al. [24] reported a decline in eGFR of $1.91 \sim 4.19 \mathrm{ml} / \mathrm{min} /$ $1.73 \mathrm{~m}^{2}$ per $1-\mathrm{mg} / \mathrm{dl}$ increment in uric acid, indicative of a role of uric acid in CKD progression. The OR for CKD of 1.4 (95\% CI, 1.1 1.8) per $1-\mathrm{mg} / \mathrm{dl}$ increment in uric acid, which does not conflict with previous findings by Ficociello et al. [25], who demonstrated a significant association between uric acid and the development of early GFR loss. Sumiyoshi et al. [26] and Nagahama et al. [15] reported that higher uric acid levels were independently associated with a greater risk of incident metabolic syndrome and that hyperuricemia tends to have a clustering of cardiovascular risk factors. In addition, Antonini et al. [27] showed that carotid arterial stiffness is related to uric acid, independently of established cardiovascular risk factors. Although pre-donation hyperuricemia is not included in the donor evaluation guidelines [7], caution should be exerted when hyperuricemia is detected in a donor, regardless of normal renal function.

Some limitations of our study were that it was a single-institution study with a small sample size; further, analysis was retrospective in nature and the follow-up term was relatively short. As biopsies are difficult to perform prior to donor selection, these findings cannot be included in the donor selection process. Additional studies are needed to investigate the added contribution of other factors to the health status of donors, such as presarcopenia, to predict chronic renal pathology from clinical findings.

\section{Conclusions}

Pathological findings in biopsy specimen at $1 \mathrm{~h}$ and higher uric acid level were associated with insufficient recovery of renal function at 1 year after donation. Living donors with hyperuricemia and a high chronicity score $(\mathrm{ah} \geqq 1 \cap \mathrm{ct}+\mathrm{ci} \geqq 1)$ should be followed up with caution after donation.

\section{Abbreviations}

Ah: Arteriolar hyalinosis; BMI: Body mass index; BSA: Body surface area; Ci: Chronic interstitial fibrosis; Cl: Confidence interval; Ct: Chronic tubular atrophy; eGFR: Estimated-glomerular filtration rate; ESRD: End-stage renal disease; IFTA: Interstitial fibrosis and tubular atrophy; JDS: Japan Diabetes Society; NGSP: National Glycohemoglobin Standardization Program

\section{Acknowledgements}

Not applicable.

\section{Authors' contributions}

SN and SY conceptualized and designed the study. YH, MT, KK, KT, CK, SH, Al $H Y$, AT and SU acquired, analyzed, or interpreted the data. SN and SY drafted the manuscript. YH, MT, KK, KT, CK, SH, Al, HY, AT and SU critically revised the manuscript for important intellectual content. SN conducted the statistical analysis. SY supervised the study. All authors have read and approved the final version of the manuscript.

\section{Funding}

Nothing to declare.

\section{Availability of data and materials}

The datasets used during the current study are available from the corresponding author on reasonable request.

\section{Ethics approval and consent to participate}

This study was approved by the Institutional Review Board of Japanese Red Cross Kumamoto Hospital (study approval number 19-290). Verbal informed consent was obtained and written informed consent was waived because of the retrospective and noninvasive nature of this study and the ethics committee approved this.

\section{Consent for publication}

Not applicable.

\section{Competing interests}

The authors declare that they have no competing interests.

\section{Author details}

'Department of General Surgery, Japanese Red Cross Kumamoto Hospital, 2-1-1 Nagamine-minami, Higashi-ku, Kumamoto 861-8520, Japan.

2Department of Urology, Japanese Red Cross Kumamoto Hospital, Kumamoto, Japan. ${ }^{3}$ Department of Internal Medicine, Japanese Red Cross Kumamoto Hospital, Kumamoto, Japan. ${ }^{4}$ Department of Nephrology, Japanese Red Cross Nagoya Daini Hospital, Myoken-cho, Japan.

Received: 11 May 2019 Accepted: 13 October 2019

Published online: 08 November 2019

\section{References}

1. Go AS, Chertow GM, Fan D, McCulloch CE, Hsu CY. Chronic kidney disease and the risks of death, cardiovascular events, and hospitalization. N Engl J Med. 2004;351(13):1296-305.

2. Anavekar NS, McMurray JJ, Velazquez EJ, Solomon SD, Kober L, Rouleau JL, et al. Relation between renal dysfunction and cardiovascular outcomes after myocardial infarction. N Engl J Med. 2004;351(13):1285-95.

3. Levey AS, de Jong PE, Coresh J, El Nahas M, Astor BC, Matsushita K, et al. The definition, classification, and prognosis of chronic kidney disease: a KDIGO controversies conference report. Kidney Int. 2011;80(1):17-28.

4. Matsushita K, van der Velde M, Astor BC, Woodward M, Levey AS, de Jong $\mathrm{PE}$, et al. Association of estimated glomerular filtration rate and albuminuria with all-cause and cardiovascular mortality in general population cohorts: a collaborative meta-analysis. Lancet. 2010;375(9731):2073-81.

5. Ohashi Y, Thomas G, Nurko S, Stephany B, Fatica R, Chiesa A, et al. Association of metabolic syndrome with kidney function and histology in living kidney donors. Am J Transplant. 2013;13(9):2342-51.

6. Japanese Society for Clinical Renal Transplantation / The Japan Society for T. Annual progress report from the Japanese renal transplant registry: number of renal transplantations in 2016 and follow-up survey. Japanese Journal of Transplantation 2017; 52(2-3):113-133.

7. Delmonico F. A report of the Amsterdam forum on the Care of the Live Kidney Donor: data and medical guidelines. Transplantation. 2005;79(6 Suppl):S53-66.

8. Lenihan CR, Busque S, Derby G, Blouch K, Myers BD, Tan JC. Longitudinal study of living kidney donor glomerular dynamics after nephrectomy. J Clin Invest. 2015;125(3):1311-8.

9. Blantz RC, Steiner RW. Benign hyperfiltration after living kidney donation. J Clin Invest. 2015;125(3):972-4.

10. Fahmy LM, Massie AB, Muzaale AD, Bagnasco SM, Orandi BJ, Alejo JL, et al. Long-term renal function in living kidney donors who had histological abnormalities at donation. Transplantation. 2016;100(6):1294-8.

11. Grams ME, Sang Y, Levey AS, Matsushita K, Ballew S, Chang AR, et al. Kidney-failure risk projection for the living kidney-donor candidate. N Engl J Med. 2016;374(5):411-21

12. Matsuo S, Imai E, Horio M, Yasuda Y, Tomita K, Nitta K, et al. Revised equations for estimated GFR from serum creatinine in Japan. Am J Kidney Dis. 2009;53(6):982-92.

13. Shimamoto K. Guidelines for managements of hypertension 2014 (JSH2014). Nihon Naika Gakkai Zasshi. 2014;103(6):1391-6.

14. Teramoto T, Sasaki J, Ishibashi S, Birou S, Daida H, Dohi S, et al. Executive summary of the Japan atherosclerosis society (JAS) guidelines for the 
diagnosis and prevention of atherosclerotic cardiovascular diseases in Japan -2012 version. J Atheroscler Thromb. 2013;20(6):517-23.

15. Nagahama K, Iseki K, Inoue T, Touma T, Ikemiya Y, Takishita S. Hyperuricemia and cardiovascular risk factor clustering in a screened cohort in Okinawa. Japan. Hypertens Res. 2004;27(4):227-33.

16. Haas M, Sis B, Racusen LC, Solez K, Glotz D, Colvin RB, et al. Banff 2013 meeting report: inclusion of c $4 \mathrm{~d}$-negative antibody-mediated rejection and antibody-associated arterial lesions. Am J Transplant. 2014;14(2):272-83.

17. Kasiske BL, Anderson-Haag T, Ibrahim HN, Pesavento TE, Weir MR, Nogueira $J \mathrm{M}$, et al. A prospective controlled study of kidney donors: baseline and 6 month follow-up. Am J Kidney Dis. 2013;62(3):577-86.

18. Kasiske BL, Anderson-Haag T, Israni AK, Kalil RS, Kimmel PL, Kraus ES, et al. A prospective controlled study of living kidney donors: three-year follow-up. Am J Kidney Dis. 2015;66(1):114-24.

19. Imai E, Horio M, Yamagata K, Iseki K, Hara S, Ura N, et al. Slower decline of glomerular filtration rate in the Japanese general population: a longitudinal 10-year follow-up study. Hypertens Res. 2008;31(3):433-41.

20. Moranne O, Froissart M, Rossert J, Gauci C, Boffa JJ, Haymann JP, et al. Timing of onset of CKD-related metabolic complications. J Am Soc Nephrol. 2009;20(1):164-71.

21. Turin TC, James MT, Jun M, Tonelli M, Coresh J, Manns BJ, et al. Short-term change in eGFR and risk of cardiovascular events. J Am Heart Assoc. 2014; 3(5):e000997.

22. Li X, Zhuang S. Recent advances in renal interstitial fibrosis and tubular atrophy after kidney transplantation. Fibrogenesis Tissue Repair. 2014;7:15.

23. Schelling JR. Tubular atrophy in the pathogenesis of chronic kidney disease progression. Pediatr Nephrol. 2016;31(5):693-706.

24. Iseki K, Iseki C, Kinjo K. Changes in serum uric acid have a reciprocal effect on eGFR change: a 10-year follow-up study of community-based screening in Okinawa. Japan Hypertens Res. 2013;36(7):650-4.

25. Ficociello LH, Rosolowsky ET, Niewczas MA, Maselli NJ, Weinberg JM, Aschengrau A, et al. High-normal serum uric acid increases risk of early progressive renal function loss in type 1 diabetes: results of a 6-year followup. Diabetes Care. 2010;33(6):1337-43.

26. Sumiyoshi H, Ohyama Y, Imai K, Kurabayashi M, Saito Y, Nakamura T. Association of Uric Acid with incident metabolic syndrome in a Japanese general population. Int Heart J. 2019. https://doi.org/10.1536/ihj.18-444.

27. Antonini-Canterin F, Di Nora C, Pellegrinet M, Vriz O, La Carrubba S, Carerj S, et al. Effect of uric acid serum levels on carotid arterial stiffness and intimamedia thickness: A high resolution Echo-Tracking Study. Monaldi Arch Chest Dis. 2019; 89(1).

\section{Publisher's Note}

Springer Nature remains neutral with regard to jurisdictional claims in published maps and institutional affiliations.

Ready to submit your research? Choose BMC and benefit from:

- fast, convenient online submission

- thorough peer review by experienced researchers in your field

- rapid publication on acceptance

- support for research data, including large and complex data types

- gold Open Access which fosters wider collaboration and increased citations

- maximum visibility for your research: over $100 \mathrm{M}$ website views per year

At BMC, research is always in progress.

Learn more biomedcentral.com/submissions 